\title{
Speed Sensorless Vector Control of Permanent Magnet Wind Power Generator - The Redundant Drive Concept
}

\author{
Tero Halkosaari \\ Vacon Oyj \\ Finland
}

\section{Introduction}

Permanent Magnet motors (PM-motors) have become more and more popular, especially in low speed and high speed applications. The conventional motor drive, consisting of a standard speed induction motor with a gearbox, can be replaced of a very low speed, or a very high speed permanent magnet motor having no gearbox. The advantages are, for example, an increased efficiency and the reliability. Also total weight, noise and costs of the whole drive system are reduced.

Permanent magnet motors can be designed efficiently for very low running speeds by increasing the pole number. This makes permanent magnet machines very attractive for wind power generators, because in high power wind mills (> $1 \mathrm{MW})$, a wind turbine rotor is typically rotating about 10 to $20 \mathrm{rpm}$.

One important aspect of motor drives is the reliability of the drive system. Reliability comes even more important in installations, where the maintenance is difficult i.e. in wind mill nacelles. The reliability of the PM wind power generators can be increased by using multiple stator modules, or stator segments, independent of each other. These segments can be considered, for example, as independent stator parallel windings which are each fed by an own frequency converter. If one of the frequency converters fails, other ones can continue the operation while the failed units are changed. Hence, there is no long period total power interruption, because the wind turbine operation can continue anyway at a reduced power level.

This chapter describes the speed sensorless vector control of a variable speed multi-module PM wind power generator. First, the redundant drive concept is introduced based on the modular drive concept. Then, the speed sensorless vector control theory applied to wind power generators is discussed. Some emphasize is given also for the generator inverter overvoltage control, which is important in case of a grid lost. Theory and laboratory tests are shown for a $4 \times 1 \mathrm{~kW}$ PM-generator. Some test results are shown also for the real size wind power generator, which is a $3.8 \mathrm{MW} 17.5 \mathrm{rpm}$ radial flux PM-generator consisting of 3 stator modules.

\section{Drive system}

Drive topologies used in high power wind generators are still mainly conventional solutions i.e. asynchronous induction generators with a gearbox coupling. These are limited speed 
range slip-ring induction generators directly connected to the power grid and having a resistive slip-control, variable speed double-fed slip-ring induction generators with an active slip-power recovery drive, or variable speed fully controlled induction generators with a 4-quadrant drive. However, nowadays development interests are directed towards variable speed direct drives which are externally excited synchronous generators, or now more often 4-quadrant drive permanent magnet synchronous generators. The advantage of a variable speed drive is that the power can be generated already at small wind speeds and the power production can be optimized according to the wind and the generator speed. This seems to be a trend also in smaller $(20 \mathrm{~kW})$ wind power generators.

\subsection{4-quadrant VSI drive topology}

A direct drive variable speed PM wind generator system (Fig. 1) consists typically of a multi pole PM-generator, the generator side INverter Unit (INU), and the supply side Active Front End (AFE). In a Voltage Source Inverter (VSI) topology, drives are connected through the dc-link having a capacitor bank which is the momentary energy storage. LCL-filter is used in the supply side to suppress switching frequency harmonics generated by the AFE. Generator side inverter controls the generator torque according to the power reference of the generator based on the wind speed, while the active front end controls the dc-link voltage and the active and reactive power flow to the utility grid. The generator side inverter can also be used to rotate the generator in motoring mode, for example, in turbine service and installation situations.

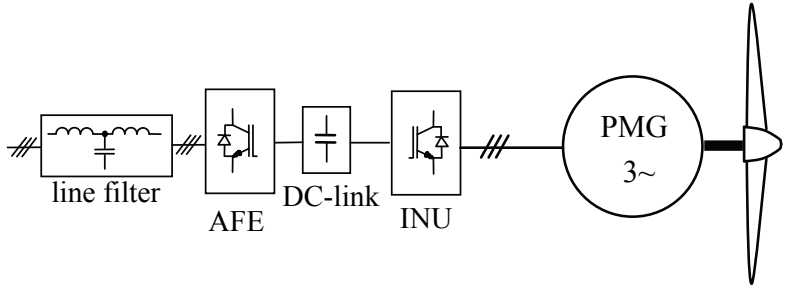

Fig. 1. A 4-quadrant VSI wind power generator drive.

\subsection{Redundant PM-generator concept}

A redundant PM-generator comprise multiple independent stator modules or segments preferably with a galvanic isolation from each other. Each module will be driven by an own inverter connected to a common dc-link and to the power grid with parallel connected AFEs. Alternatively each inverter can have an own dc-link and AFE (Fig. 2). Generator stator modules can consist of, for example, stator parallel winding groups carrying the same stator current. If winding groups are located in adjacent stator slots, there will be a voltage and a current phase shift between the winding groups. This phase shift can be compensated by the drive control and hence is not usually a problem. On the other hand, stator windings can be located in own groups in similar stator segments. For example, in (Albrich \& Fuchs, 2002), it is proposed that instead of the conventional 16-pole stator winding, windings can be arranged in four 4-pole segments, in which case segments are independent from each other and can be run by an own inverter.

In all arrangements, if there is a galvanic isolation between the segment windings, there is no need to synchronize IGBT switching instants of different segment inverters, unless there is a strong magnetic or capacitive cross-coupling between the segment windings. The 


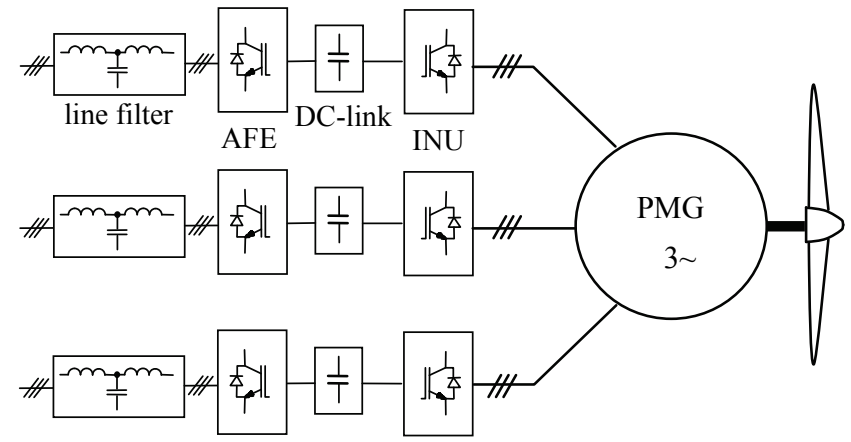

Fig. 2. Modular redundant PM wind generator drive.

cross-coupling can occur, for example, if segment windings are located in same stator slots. Strong cross-coupling means that the voltage or current transient in one drive segment will induce a transient current component to the other segment and the generator current control can fail due to the disturbance current component. Synchronization of IGBT switching instants is possible but requires more control hardware and makes the drive system more complicated. In case of drive segments are phase shifted, only partial synchronization is possible due to the phase shifted output voltages. Also if there is an own current control in each drive, a perfect synchronization is not possible due to the slight differences in segment's instantaneous voltages.

Fig. 2 modular system has several advantages. If one of the segment drive inverters fails, it can be separated from the system and the generator can continue on operation using the reduced power until the failed unit is changed. One main advantage is also that the system power can be increased by increasing the number of the stator segments while the generator power is increased. Hence there is necessarily no need to increase the power of individual inverters, just the amount of the inverters.

\section{Control of a redundant PM-generator}

\subsection{Master-follower control concept with an encoder feedback}

Optimally controlled redundant PM-generator requires the rotor speed and position information for each segment drive. Typically used position sensors are resolvers and serial data type (e.g. EnDat, SSI) absolute encoders. Typically, these encoders can deliver also the speed signal based on the separate incremental encoder pulses, sin/cos-signals or just the serial data transfer. Speed signal can also been derived from the resolver position signal with sufficient accuracy. Instead of absolute encoders, also incremental encoders can be used which are more common in industry. Then the rotor position can be calculated by summing incremental pulses, if the rotor start position is known. There are plenty of methods to identify the PM-generator start position (magnet pole position) either for standstill or rotating rotor. Also the reference-mark pulse (z-pulse) can be utilized to determine the rotor position because the z-pulse can be considered as a single step absolute encoder.

In high power wind generators, the cost of a speed and/or rotor position measurement utilizing the encoder or resolver is very small compared to the total costs of the whole wind turbine. Hence, it's mainly a question of the encoder and other system reliability, if the 
encoder is used for the generator control in order to have an accurate speed and shaft position measurement. In case of the encoder failure, the whole wind mill has to be stopped, if there are no backup devices. It is also difficult to avoid disturbances in encoder cables, because there is usually not much space to separate the power cables from the signal cables in a wind turbine nacelle. Anyway, some kind of speed measurement is required due to the safety but these can be robust low resolution devices, such as inductive sensors.

In a redundant drive concept, the simplest solution is to have multiple encoders, one for each of drive units. However, that it is not a mechanically robust and reliable solution, if there are more than two encoders. Another solution is to use one encoder and to repeat the encoder signal for each drive. Repeating encoder signals using commercial repeaters can be difficult depending on the type of encoder signals. A relatively simple solution (Fig. 3) is that one of the drives behaves as the repeater i.e. as a master drive which receives encoder signals and other command signals from the overriding system controller. The master drive sends further the processed speed and position information and other command signals to the other drives called followers. Hence, followers are able to track instantaneous currents of the master drive (Mäkinen \& al, 2006).

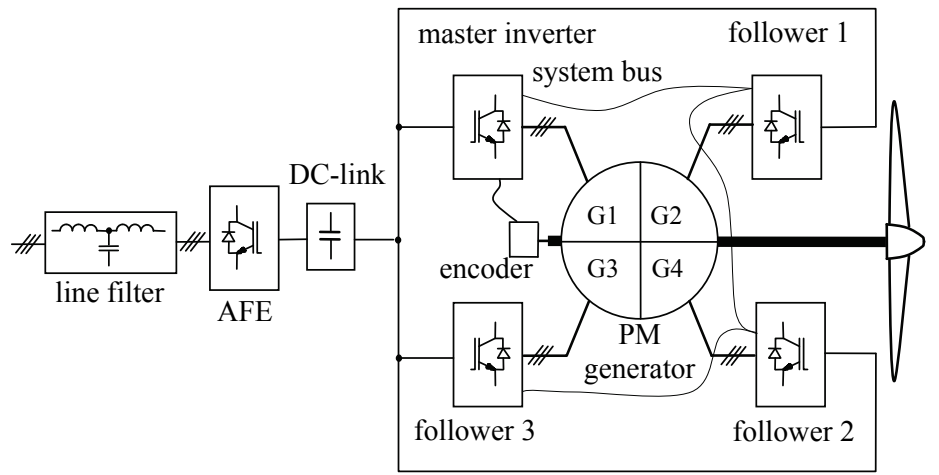

Fig. 3. Master-follower type control of 4-segment PM-generator with an encoder feedback.

Communication link between the master and follower drives can be done via the optical serial data link in order to avoid disturbances. The link can also be a galvanic bus, for example, a CAN-bus was tested in the drive test setup. The benefit of a galvanic bus is that the bus is always continuous from the first drive to the last drive and not depending on any auxiliary power like optical bus repeaters do. In case of the master drive inverter fails, one of the follower drives can be switched to be a master drive in order to continue the operation. In this master-follower configuration also the segment phase shift is easily implemented by shifting the follower current reference phase angle received from the master by the amount of each segment phase shift.

\subsection{Speed sensorless control concept}

In order to increase the drive system reliability, speed and position sensorless vector control can be used. In fact, the wind power generation is one of the applications which is very attractive for the sensorless vector control. First of all, there is no need to start the rotor at standstill or even to drive in a low speed area. Especially, driving the high torque at a low 
speed has been the most challenging and unreliable part of sensorless control methods. Typically, the wind generator is started and operated at speed above $15 \%$ of the generator nominal speed. Hence, the flying start can be used to start the generator side inverter. The flying start is easily implemented, because the generator back e.m.f. voltage is already high enough to identify the rotor position and speed. Second, there is no need for a high torque at low speed region, because the generator power increases rapidly not until the speed is closer to the nominal speed of the generator. It is not usually a problem to identify the rotor position and the speed in high speed region whatever the torque is. In fact, even the speed estimation is not needed for the generator control because inverters are operating typically in torque control mode and the speed control loop is not used. However, the generator speed is usually the essential information for the overriding generator controller. Third, because each of the inverters is identifying independently the rotor speed and the position, there is no need for the communication between the units (Fig. 4). Only commands needed for each drive are low speed commands from the overriding control system which can be delivered to each drive using drive I/O-signals or industry standard buses e.g. Profibus.

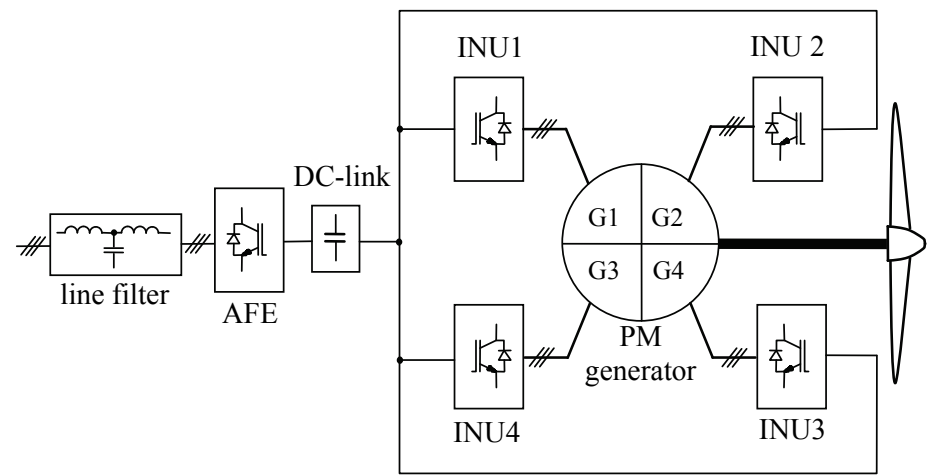

Fig. 4. Speed and position sensorless control of a 4-segment PM-generator.

\subsection{Speed sensorless vector control}

Speed sensorless vector control means that the generator current is controlled into a right angle with respect to the rotor magnet flux for the maximal torque production. Generator torque equation is defined as

$$
T_{\mathrm{e}}=\frac{3}{2} p\left(\underline{\Psi}_{\mathrm{s}} \times \underline{i}_{\mathrm{s}}\right)=\frac{3}{2} p\left(\psi_{\mathrm{m}} i_{\mathrm{q}}+\left(L_{\mathrm{d}}-L_{\mathrm{q}}\right) i_{\mathrm{d}} i_{\mathrm{q}}\right)
$$

where the first term is the torque produced by the magnet flux $\Psi_{\mathrm{m}}$ and the last term is the reluctance torque. According to equation (1), the right control angle means for smooth air gap machines $\left(L_{\mathrm{d}}=L_{\mathrm{q}}\right)$ that the current phasor is leading the magnet flux phasor by $90^{\circ}$ i.e. machine $\mathrm{d}$-axis current is kept zero and the generator takes only the q-axis torque producing current (Fig. 5). For salient pole machines $\left(L_{\mathrm{d}}<L_{\mathrm{q}}\right)$, some amount of additive reluctance torque can be produced by a negative d-axis current. This requires that the $\mathrm{d}$-axis current is controlled as a function of q-axis current according to the Maximum Torque Per Ampere (MTPA) optimization. In order to divide the generator current into the $\mathrm{d}$ - and q-axis 
components, rotor magnet flux i.e. the rotor magnet pole position $\theta_{\mathrm{r}}$ must be known all the time. There are a lot of different estimation methods for the rotor position and the speed. Main estimation techniques are such as; estimators based on the motor back e.m.f. voltage identification, estimators based on the Kalman-filters, estimators based on the state observers, estimators based on the stator flux identification such as the Model Reference Adaptive System (MRAS), and estimators based on the external signal injection into the motor. For simplicity, the MRAS (Andreescu, 1999) estimator is used, which is not a computationally intensive method.

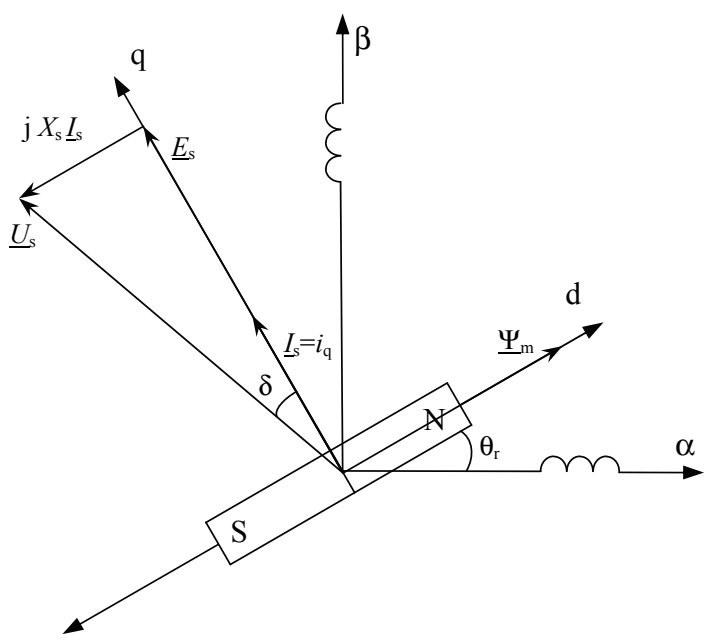

Fig. 5. Smooth air gap PM-motor voltage and current vector presentation in a rotor flux (d-q) frame of reference.

\subsection{MRAS speed and position estimator}

MRAS is based on the stator flux identification by using the motor mathematical model utilizing measured motor currents and voltages (Fig. 6). First, the stator flux is calculated based on motor voltages using the voltage model which is the reference model. On the other hand, the stator flux is calculated based on motor currents and the estimated rotor flux position using the current model which is the adaptive model. If there is an estimation error in the rotor flux position, the error is directly seen in a stator flux phase angle obtained from the current model. Hence, by comparing the stator flux vector phase angle of the current model to the stator flux vector phase angle of the voltage model, one can obtain the flux error angle. This error angle is used to correct the estimated rotor speed in a way that the error angle converges towards the zero. Correction mechanism i.e. the adaptation mechanism in this case is a simple PI-controller which input is the flux error angle and the output is the estimated speed. Estimated rotor flux angle is obtained by integrating the rotor speed. For simplicity, only a smooth air gap machine is considered i.e. it is assumed that the generator has $L_{\mathrm{d}}=L_{\mathrm{q}}$, which is a reasonable assumption for most of the generators with surface mounted magnets. However, the generator saliency can be included in the current model. 


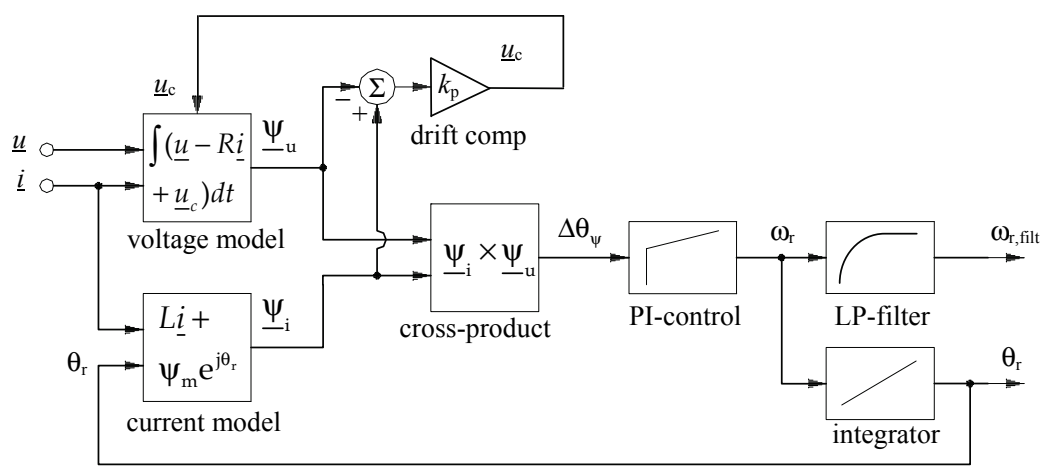

Fig. 6. MRAS estimator for the rotor speed and position estimation.

\subsubsection{MRAS current model}

Current model can be built utilizing the synchronous $\mathrm{d}-\mathrm{q}$ frame of reference or the stationary $\alpha-\beta$ frame of reference. Stationary frame of reference is better in a way that it uses directly measured stator currents and voltages. Instead, the synchronous frame of reference uses converted $\mathrm{d}$ - and q-axis values, which are calculated based on the estimated rotor flux position which is not an exact value. Synchronous frame presentation is more simple in case of generator has salient poles but for smooth air gap machines there is not much computational difference. Current model in a stationary frame of reference is obtained from the PM-machine stator flux equations as

$$
\begin{aligned}
& \psi_{\mathrm{i} \alpha}=L_{\mathrm{s}} i_{\alpha}+\psi_{\mathrm{m}} \cos \left(\theta_{\mathrm{r}}\right), \\
& \psi_{\mathrm{i} \beta}=L_{\mathrm{s}} i_{\beta}+\psi_{\mathrm{m}} \sin \left(\theta_{\mathrm{r}}\right),
\end{aligned}
$$

where $\theta_{\mathrm{r}}$ is the estimated rotor flux position. In this case it's also assumed that there is no machine saliency i.e. $L_{\mathrm{d}}=L_{\mathrm{q}}=L_{\mathrm{s}}$. In synchronous frame of reference, equations (2) - (3) are presented as

$$
\begin{gathered}
\psi_{\mathrm{d}}=L_{\mathrm{d}} i_{\mathrm{d}}+\psi_{\mathrm{m}}=L_{\mathrm{s}} i_{\mathrm{d}}+\psi_{\mathrm{m}}, \\
\psi_{\mathrm{q}}=L_{\mathrm{q}} i_{\mathrm{q}}=L_{\mathrm{s}} i_{\mathrm{q}} .
\end{gathered}
$$

\subsubsection{MRAS voltage model}

PM-machine voltage equations in a stationary frame of reference are given as

$$
\begin{aligned}
& u_{\alpha}=R i_{\alpha}+\frac{d \psi_{\alpha}}{d t}, \\
& u_{\beta}=R i_{\beta}+\frac{d \psi_{\beta}}{d t} .
\end{aligned}
$$


MRAS voltage model calculates stator flux components by integrating stator voltages. Using equations (6) and (7), flux components are obtained as

$$
\begin{aligned}
& \psi_{\mathrm{u} \alpha}=\int\left(u_{\alpha}-R i_{\alpha}\right) d t \\
& \psi_{\mathrm{u} \beta}=\int\left(u_{\beta}-R i_{\beta}\right) d t .
\end{aligned}
$$

Equations (8) and (9) include the open integration, which means that the calculated stator flux vector tends to drift away from the origin due to the measurement and parameter errors. This can be avoided by replacing the integration algorithm by low-pass filters, or other algorithms tracking the behavior of integrator such as presented in ( $\mathrm{Hu} \& \mathrm{Wu}, 1998)$. In this case, a corrective voltage term $\underline{u}_{c}$ (Andreescu, 1999) is added inside the integration giving

$$
\begin{aligned}
& \psi_{\mathrm{u} \alpha}=\int\left(u_{\alpha}-R i_{\alpha}+u_{c \alpha}\right) d t, \\
& \psi_{\mathrm{u} \beta}=\int\left(u_{\beta}-R i_{\beta}+u_{c \beta}\right) d t .
\end{aligned}
$$

This correction term forces the calculated stator flux vector back to the origin. Correction voltage is obtained by comparing the current model flux components to the voltage model flux components at slower execution time level than the integration operation is performed according to

$$
\begin{aligned}
& u_{\mathrm{c} \alpha}=k_{\mathrm{p}}\left(\psi_{\mathrm{i} \alpha}-\psi_{\mathrm{u} \alpha}\right), \\
& u_{\mathrm{c} \beta}=k_{\mathrm{p}}\left(\psi_{\mathrm{i} \beta}-\psi_{\mathrm{u} \beta}\right) .
\end{aligned}
$$

Because the stator flux vector obtained from the current model is always centered at the origin, the voltage correction term forces the stator flux obtained from the voltage model also towards the origin.

\subsubsection{Stator flux error angle}

Stator flux error angle is obtained from the angle difference of the voltage model stator flux vector and the current model stator flux vector. This can be calculated, for example, by using the cross-product of these two stator flux vectors. The cross-product is given as

$$
\underline{\psi}_{\mathrm{u}} \times \underline{\psi}_{\mathrm{i}}=\psi_{\mathrm{u}} \psi_{\mathrm{i}} \sin \left(\Delta \theta_{\psi}\right)=\psi_{\mathrm{u}, \beta} \psi_{\mathrm{i}, \alpha}-\psi_{\mathrm{u}, \alpha} \psi_{\mathrm{i}, \beta} .
$$

The cross-product is zero, if estimated stator flux vectors are aligned. For small error angles, stator flux error angle is obtained from (14) as

$$
\Delta \theta_{\psi} \approx \sin \left(\Delta \theta_{\psi}\right)=\frac{\psi_{\mathrm{u}, \beta} \psi_{\mathrm{i}, \alpha}-\psi_{\mathrm{u}, \alpha} \psi_{\mathrm{i}, \beta}}{\psi_{\mathrm{u}} \psi_{\mathrm{i}}}
$$

\subsection{Rotor flux oriented vector control}

A simplified control diagram for the overall closed loop control system is shown in Fig. 7. Torque control block defines the q-axis current reference $i_{\mathrm{q}, \text { ref }}$ for the q-axis current 
controller. Torque controller inputs comprise the torque reference and the estimated actual torque. The actual torque calculation is based on the equation (1) and the torque reference is calculated typically as a function of the wind speed. MTPA block defines the d-axis current reference $i_{\mathrm{d} \text {,ref }}$ for the $\mathrm{d}$-axis current controller as a function of the $i_{\mathrm{q}}$-current. For smooth air gap machines, the $\mathrm{d}$-axis current is referenced to zero, which gives the name ' $i_{\mathrm{d}}=0$ ' control. In the field-weakening area, the field-weakening controller outputs an additional d-axis current reference. Current controllers ensure the fast tracking of current references by output voltage control using the Space Vector Modulator (SVM).

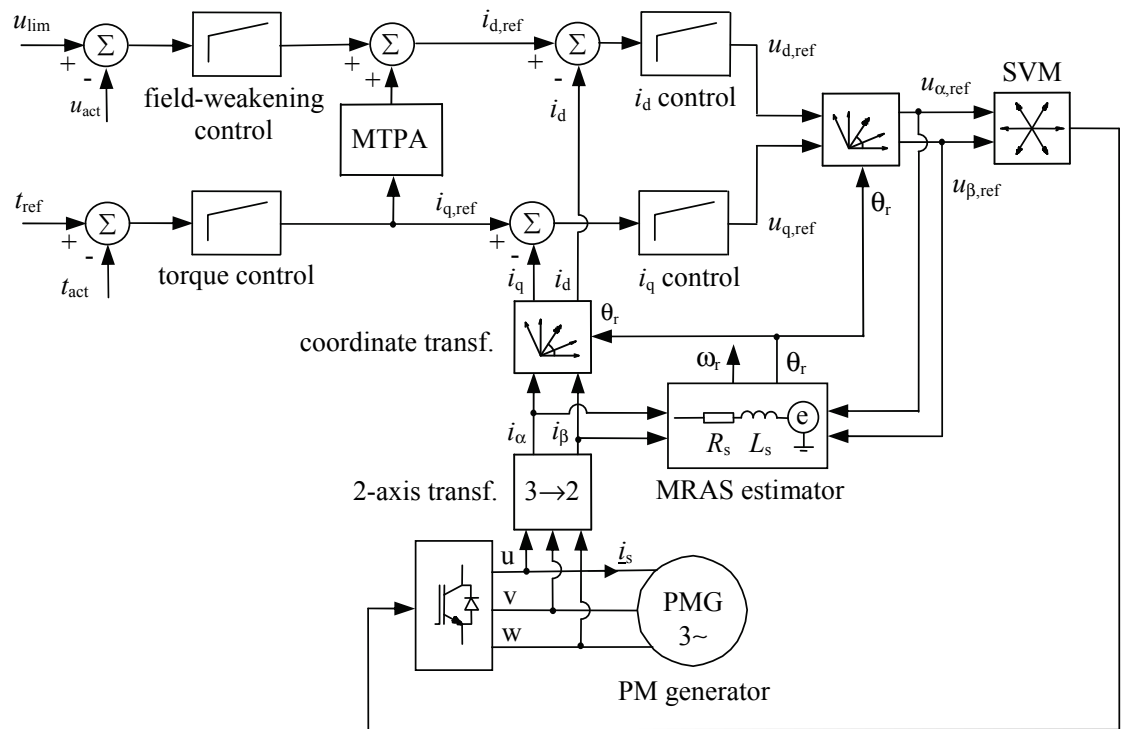

Fig. 7. A simplified block diagram of the speed sensorless control system

\subsubsection{Field-weakening control}

Field-weakening control is based on the reduction of the d-axis stator flux, which in turn reduces the stator voltage. According to the equation (4), stator flux can be reduced by injecting the negative d-axis current into the generator. Field-weakening controller inputs comprise the maximum motor voltage limit reference and the actual motor voltage. There is no need to measure the actual voltage because it can be calculated accurate enough based on voltage references. Due to the field-weakening controller, generator can operate also in the field-weakening area (constant power area), where the generator stator voltage is limited to the maximum voltage inverter is capable to produce. The extra $i_{\mathrm{d}}$ current needed depends on the generator design and is defined by

$$
i_{\mathrm{d}}=-\frac{\psi_{\mathrm{m}}}{L_{\mathrm{d}}}+\frac{1}{L_{\mathrm{d}}} \sqrt{\frac{u_{\mathrm{lim}}^{2}}{\omega_{\mathrm{r}}^{2}}-\left(L_{\mathrm{q}} i_{\mathrm{q}}\right)^{2}},
$$

where $u_{\text {lim }}$ is the maximum voltage limit and $\omega_{\mathrm{r}}$ is the rotor speed. Note, that in the equation (16), the stator resistance is neglected because it has only a small affect in field-weakening 
area. In practice, there is no need to calculate the field-weakening current based on the equation (16), because the PI-controller will automatically adjust the current in the level defined by the equation (16). Extra $i_{\mathrm{d}}$-current component in a field-weakening operation means a higher generator current. Because the maximum thermal current limit of the inverter and the generator cannot be exceeded for a long period, the q-axis current must be limited in a field-weakening operation according to the required d-axis current and the current limit. Fig. 8 shows an example how the $i_{\mathrm{d}^{-}}$and the total current behave as a function of the $\mathrm{i}_{\mathrm{q}}$-current with a fixed speed and voltage limit.

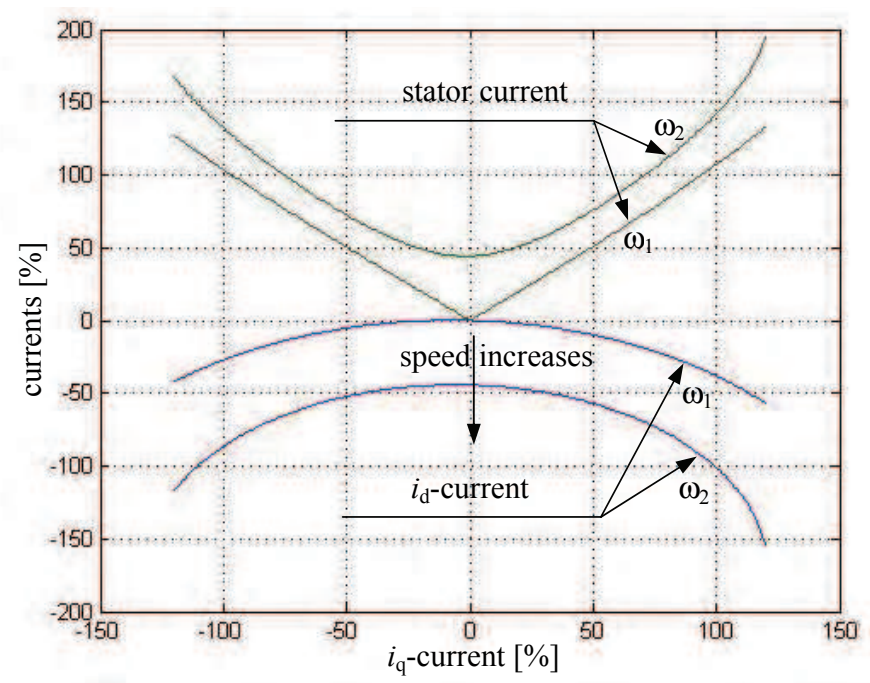

Fig. 8. Smooth air gap machine field-weakening currents as a function of $i_{\mathrm{q}}$-current with a constant voltage limit and given speeds $\omega_{1}<\omega_{2}\left(R_{\mathrm{s}}\right.$ is included in calculation).

\subsubsection{MTPA optimization}

Maximum Torque Per Ampere optimization gives the basic $i_{\mathrm{d}}$-current reference. The target is that the generator produces the maximum torque using the minimum current. For smooth air gap machines, the optimal $i_{\mathrm{d}}$-current reference equals to zero. Instead, for salient pole machines some extra torque can be produced by feeding the negative $i_{\mathrm{d}}$-current into the generator. $I_{\mathrm{d}}$-current needed, can be found by solving the torque global maximum with respect to the motor current using the motor torque equation (1). This gives the motor $i_{\mathrm{d}}$-current reference as

$$
i_{\mathrm{d}}=\frac{\psi_{\mathrm{m}}}{2\left(L_{\mathrm{q}}-L_{\mathrm{d}}\right)}-\sqrt{\frac{\psi_{\mathrm{m}}^{2}}{4\left(L_{\mathrm{q}}-L_{\mathrm{d}}\right)^{2}}+i_{\mathrm{q}}^{2}} .
$$

Typically, for salient pole PM-machines $L_{\mathrm{d}}$ is lower than $L_{\mathrm{q}}$, and the equation (17) results in a negative id-current reference (Fig. 9). 


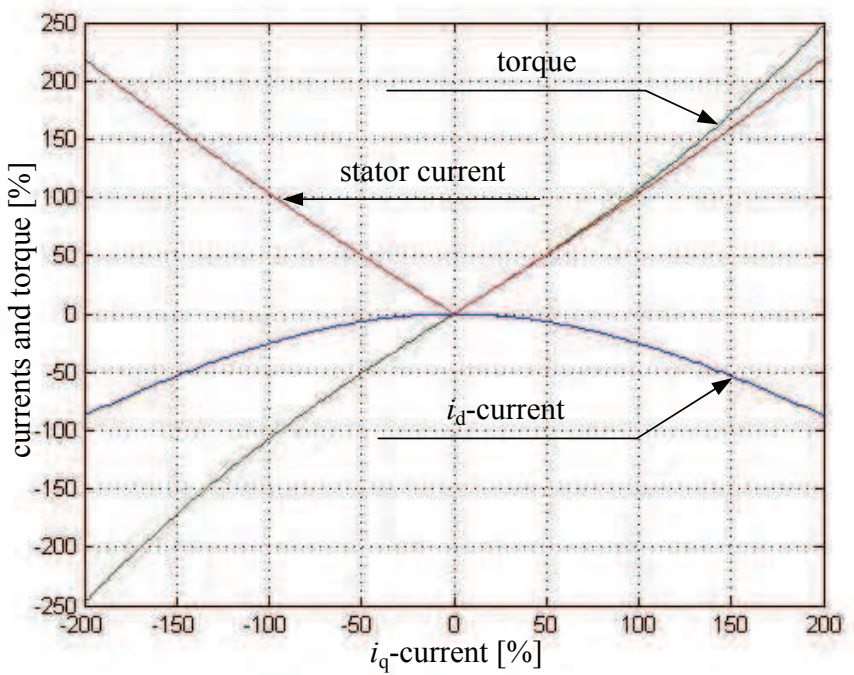

Fig. 9. Salient pole machine currents and torque according to the MTPA optimization (as an example $L_{\mathrm{d}, \mathrm{pu}}-L_{\mathrm{q}, \mathrm{pu}}=-0.27$ p.u. and $\left.L_{\mathrm{d}, \mathrm{pu}} / L_{\mathrm{q}, \mathrm{pu}}=0.55\right)$.

\subsection{3 $\operatorname{Cos}(\varphi) \operatorname{ctrl}$}

PM-generator $\cos (\varphi)$ can be controlled by feeding the extra $i_{\mathrm{d}}$-current to the machine. Negative $i_{\mathrm{d}}$-current produces the reactive power, which means that the machine $\cos (\varphi)$ can be improved by a negative $i_{\mathrm{d}}$-current injection. This means also that the MTPA-optimization and the field-weakening control tend to improve the generator power factor. Normally, there is no need for an additional $\cos (\varphi)$ control. MTPA-optimization for salient pole machines, and ' $i_{\mathrm{d}}=0^{\prime}$ control for smooth air gap machines give already the optimal performance i.e. the maximum torque with a minimum current. Negative $i_{\mathrm{d}}$-current advances the current vector angle and reduces the motor voltage (Fig. 10). Additional $i_{\mathrm{d}}$-current component means also a higher stator current which increases the machine copper losses and the drive current rating. On the other hand, the lower stator voltage means the lower stator flux which in turn decreases machine iron losses. Motor $\cos (\varphi)$ can be improved up to the maximum $\cos (\varphi)=1$. For $\cos (\varphi)=1$ control, $i_{\mathrm{d}}$-current can be calculated as a function of the $i_{\mathrm{q}}$-current giving

$$
i_{\mathrm{d}}=-\frac{\psi_{\mathrm{m}}}{2 L_{\mathrm{d}}}+\sqrt{\frac{\psi_{\mathrm{m}}^{2}}{4 L_{\mathrm{d}}{ }^{2}}-\frac{L_{\mathrm{q}}}{L_{\mathrm{d}}} i_{\mathrm{q}}^{2}} .
$$

It can be concluded from the equation (18) that there is a maximum $i_{\mathrm{q}}$-current limit above the $\cos (\varphi)=1$ control is not any more possible. This condition is given as

$$
\left|i_{\mathrm{q}}\right| \leq \frac{\psi_{\mathrm{m}}}{2 \sqrt{L_{\mathrm{d}} L_{\mathrm{q}}}} .
$$




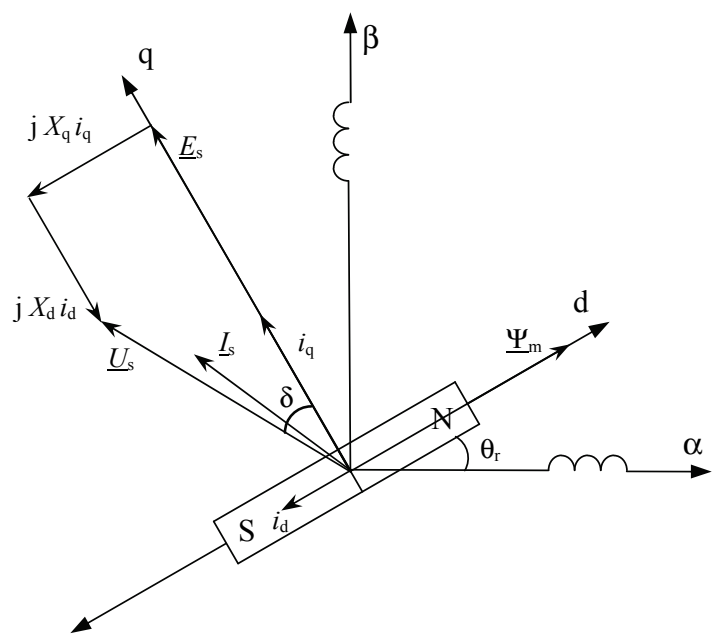

Fig. 10. PM-motor voltage and current vector presentation with $i_{\mathrm{d}}$-current.

For smooth air gap machines $L_{\mathrm{d}}=L_{\mathrm{q}}=L_{\mathrm{s}}$ and the equation (19) gives

$$
\left|i_{\mathrm{q}}\right| \leq \frac{\Psi_{\mathrm{m}}}{2 L_{\mathrm{s}}}=\frac{E}{2 X_{\mathrm{s}}},
$$

where $E=\omega_{\mathrm{r}} \Psi_{\mathrm{m}}$ is the motor back e.m.f voltage and $X_{\mathrm{s}}=\omega_{\mathrm{r}} L_{\mathrm{s}}$ is the stator reactance. Equation (20) means in p.u. values that, if the motor stator inductance is more than 0.5 p.u., $\cos (\varphi)=1$ control must be restricted even when the motor operates below the nominal

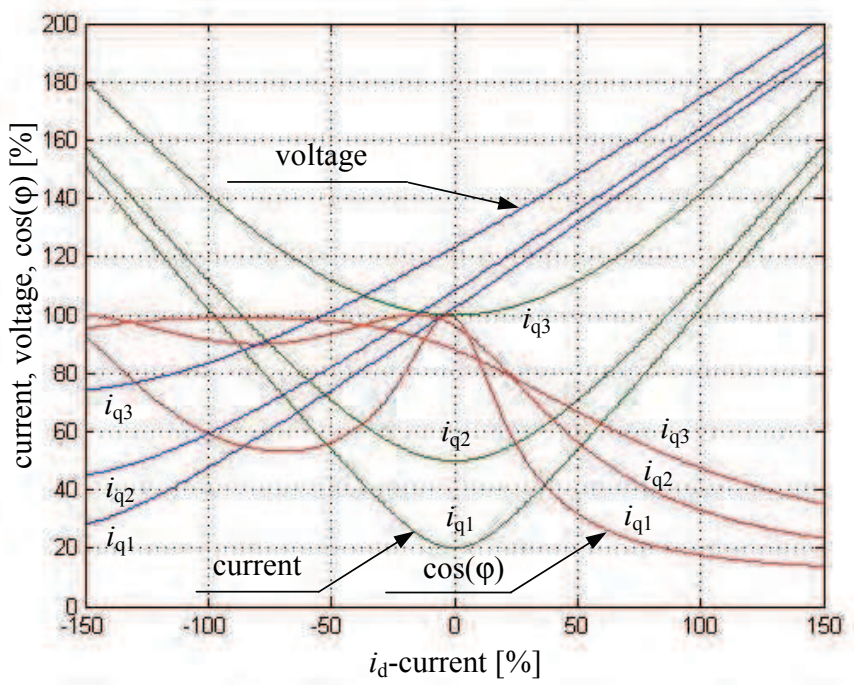

Fig. 11. Motor stator voltage, stator current and $\cos (\varphi)$ as a function of $i_{\mathrm{d}}$-current for different load points $i_{\mathrm{q} 1}=0.2$ p.u., $i_{\mathrm{q} 2}=0.5$ p.u., $i_{\mathrm{q} 3}=1.0$ p.u. ( $L_{\mathrm{d}}=L_{\mathrm{q}}=0.59$ p.u.). 
torque point. Fig. 11 shows an example how the motor $\cos (\varphi)$ and the stator voltage behave as a function of negative $i_{\mathrm{d}}$-current in three load points. $\operatorname{Cos}(\varphi)=1$ point can be found corresponding to the $i_{\mathrm{d}}$-current according to the equation (18).

\subsubsection{Pull-out torque}

Pull-out torque defines the maximum torque generator is capable to produce. Trying to get out more torque, generator pulls out the synchronism. Pull-out torque is normally not an issue in windmill applications. Typically, the generator torque or the thermal current limit is the first torque limiter below the pull-out torque limit. Also, the generator operation area is not heavily in field-weakening area where the pull-out torque reduces approximately inverse proportional to the speed. Neglecting the machine stator resistance, pull-out torque is defines as

$$
T_{\max }=\frac{3 p}{\omega_{\mathrm{r}}}\left[\frac{U_{\max } \psi_{\mathrm{m}}}{L_{\mathrm{d}}} \sin (\delta)+\frac{L_{\mathrm{d}}-L_{\mathrm{q}}}{2 \omega_{\mathrm{r}} L_{\mathrm{q}} L_{\mathrm{d}}} U_{\max }^{2} \sin (2 \delta)\right],
$$

where $\omega_{\mathrm{r}}$ is the rotor electrical angular speed, $p$ is the pole pair number, $U_{\max }$ is the maximum voltage of the generator and $\delta$ is the power angle. The first term in equation (21) corresponds to the torque produced by the magnet flux and the second term the reluctance torque. It can be seen that the first term, torque produced by the magnet flux, is reduced inverse proportional to rotor speed when stator voltage is limited to the maximum value.

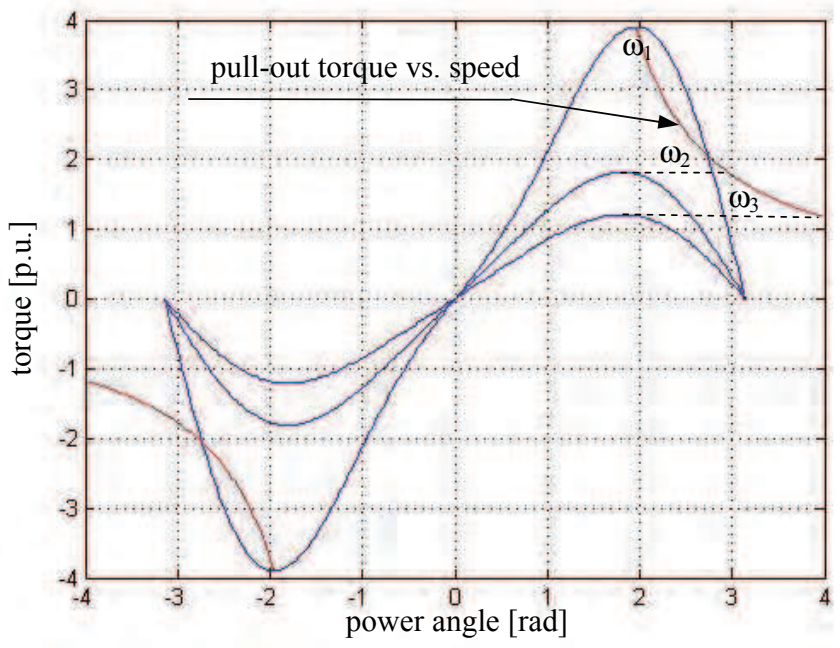

Fig. 12. Salient pole PM-machine torque characteristics at various speeds $\omega_{1}=1$ p.u., $\omega_{2}=2$ p.u., $\omega_{3}=3$ p.u. (as an example $L_{\mathrm{d}, \mathrm{pu}}-L_{\mathrm{q}, \mathrm{pu}}=-0.27$ p.u. and $L_{\mathrm{d}, \mathrm{pu}} / L_{\mathrm{q}, \mathrm{pu}}=0.55$ ).

This corresponds to the operation in the field-weakening area, which is called also a constant power region. In the field-weakening area, the second term i.e. the reluctance torque vanishes more rapidly by inverse proportional to the square of rotor speed. For salient pole PM-machines the d-axis inductance $L_{d}$ is usually smaller that the q-axis inductance $L_{\mathrm{q}}$. This means that the reluctance torque, in addition to increasing the pull-out 
torque, increases also the power angle corresponding to the pull-out torque. Power angle corresponding to pull-out torque can be found by solving the zero of the derivative of the equation (21) with respect to the power angle. Unfortunately, the resulting equation is a transcendental equation which must be solved using iterative methods. Fig. 12 shows, as an example, the torque curve for a salient pole machine at various speeds in field-weakening region.

\subsubsection{Dc-link overvoltage control}

In a normal operation mode, the AFE drive takes care of the dc-link voltage control by regulating the active power flow into the utility grid. In case of sudden supply lost, active power cannot anymore generated into the grid. This means that all the power generated will be pushed in to the dc-link capacitors following that the dc-link voltage will start to rise. If no protection is available, such as an overvoltage control, brake choppers and resistors or crowbars, the dc-link voltage can increase such a high level that destroys the drive units. Need for the external hardware overvoltage protection depends a lot of whole drive system design: how big are the dc-link capacitors, what is the maximum generator back e.m.f. voltage, how much energy is stored in stator inductances etc. In addition to hardware protection, software protection can be used. Obviously in this kind of fault situation, the generator power production must be stopped as fast as possible. In practice it means that the generator control must limit the generative torque down to zero as fast as possible in order to limit the energy pushed to the dc-link. Time needed to bring the torque down to zero depends on the generator characteristics and the operation point before the fault happens. Generator current dynamics is obtained from the synchronous frame voltage equations as

$$
\begin{gathered}
L_{\mathrm{d}} \frac{d i_{\mathrm{d}}}{d t}=u_{\mathrm{d}}-R i_{\mathrm{d}}+\omega_{\mathrm{r}} L_{\mathrm{q}} i_{\mathrm{q}} \\
L_{\mathrm{q}} \frac{d i_{\mathrm{q}}}{d t}=u_{\mathrm{q}}-R i_{\mathrm{q}}-\omega_{\mathrm{r}}\left(L_{\mathrm{d}} i_{\mathrm{d}}+\psi_{\mathrm{m}}\right) .
\end{gathered}
$$

In a generative operation, the sign of the $i_{\mathrm{q}}$-current and the torque is negative by assuming the positive speed direction. Hence, bringing the negative torque down to zero means a positive derivative of $i_{\mathrm{q}}$-current i.e. $d i_{\mathrm{q}} / d t>0$. By neglecting the stator resistance, equation (23) gives

$$
L_{\mathrm{q}} \frac{d i_{\mathrm{q}}}{d t}=u_{\mathrm{q}}-\omega_{\mathrm{r}} L_{\mathrm{d}} i_{\mathrm{d}}-e,
$$

where $e=\Psi_{\mathrm{r}} \omega_{\mathrm{r}}$ is the generator back e.m.f voltage. In addition, if it's assumed that the $i_{\mathrm{d}}$-current equals to zero, which is true for ' $i_{\mathrm{d}}=0$ ' control in constant torque region, equation (24) gives

$$
L_{\mathrm{q}} \frac{d i_{\mathrm{q}}}{d t}=u_{\mathrm{q}}-e .
$$

Generator back e.m.f voltage $e$ can be assumed to be a constant value during a fast current transient. This means that in order to control the generative torque down to a zero as fast as 
possible, controller must increase the q-axis voltage $u_{\mathrm{q}}$ as high and fast as possible. However, higher the generator torque is, the higher is the generator speed and voltage in wind power generators. This means that in a worst case, in a full power operation point, the generator operates at the full voltage and the generator has a high back e.m.f voltage. Hence, there is no margin to increase the voltage any more. Then it is not the overvoltage or the current controller dynamics, which limits the current and torque derivative but rather the lack of the sufficient voltage. A simple calculation for an example generator with $\Delta i_{\mathrm{q}}=1$ p.u., $u_{\mathrm{qmax}}=1.15$ p.u., $e=1$.p.u. and $L_{\mathrm{q}}=0.5$ p.u. yields the torque fall time $6.2 \mathrm{~ms}$, which is much more than the typical current controller step-response time. In order to force the $i_{\mathrm{q}}$-current faster towards to zero, $i_{\mathrm{d}}$-current can be utilized and equation (24) can be written as

$$
L_{\mathrm{q}} \frac{d i_{\mathrm{q}}}{d t}=u_{\mathrm{q} 2}-e=\left(u_{\mathrm{q}}-\omega_{\mathrm{r}} L_{\mathrm{d}} i_{\mathrm{d}}\right)-e .
$$

Hence, the effective voltage $u_{\mathrm{q} 2}$ can be increased with the negative $i_{\mathrm{d}}$-current which brings the current towards to zero much faster and reduces the energy pushed to the dc-link.

\section{Test results}

\subsection{A $4 \mathrm{~kW}$ four segment motor}

The redundant generator control principle was tested in a laboratory with a radial flux PMmotor comprising four independent stator segments. Each stator segment was fed with a Vacon NXP frequency converter. The generator was coupled to the asynchronous induction motor which was used to rotate the generator. Generator parameters for a one stator segment are: $R_{\mathrm{s}}=3 \Omega(7.8 \%), L_{\mathrm{s}}=60 \mathrm{mH} \quad(50.1 \%), E_{\mathrm{n}}=262 \mathrm{~V} \quad(78.8 \%), \mathrm{n}=765 \mathrm{rpm}$, $f_{\mathrm{n}}=102 \mathrm{~Hz}, p=8, I_{\mathrm{n}}=2.5 \mathrm{~A}$.

\subsubsection{Closed loop control with an encoder}

First, the closed loop control was tested with an EnDat absolute encoder feedback corresponding to the principle shown in Fig. 3. In this case, the encoder signal was wired only to one of the drives which was considered as the master drive. The master drive sends the necessary information such as the shaft position, torque reference, and the run command to the follower drives using the system bus, in this case a fiber optic bus. The generator is rotated by an asynchronous motor at $15 \%$ speed while the inverters are started with a full $100 \%$ generative torque command. Fig. 13 shows the measured U-phase currents for a master inverter and two of the followers. As expected, the currents of each drive are synchronized with respect to each other producing the optimal instantaneous total generator torque.

\subsubsection{Sensorless control without the encoder}

The test corresponding to the closed loop test with the encoder was repeated with the sensorless control corresponding to the principle shown in Fig. 4. Compared to the control with the encoder, the drive system is simpler: there is no encoder and no extra communication needed between the drives. Each drive is independently identifying the own rotor flux position and the speed. As in test with the encoder, currents are in phase synchronized with respect to each other (Fig. 14). It was also measured that the torque generated was the same w/o the encoder (Halkosaari, 2007). The main difference compared 

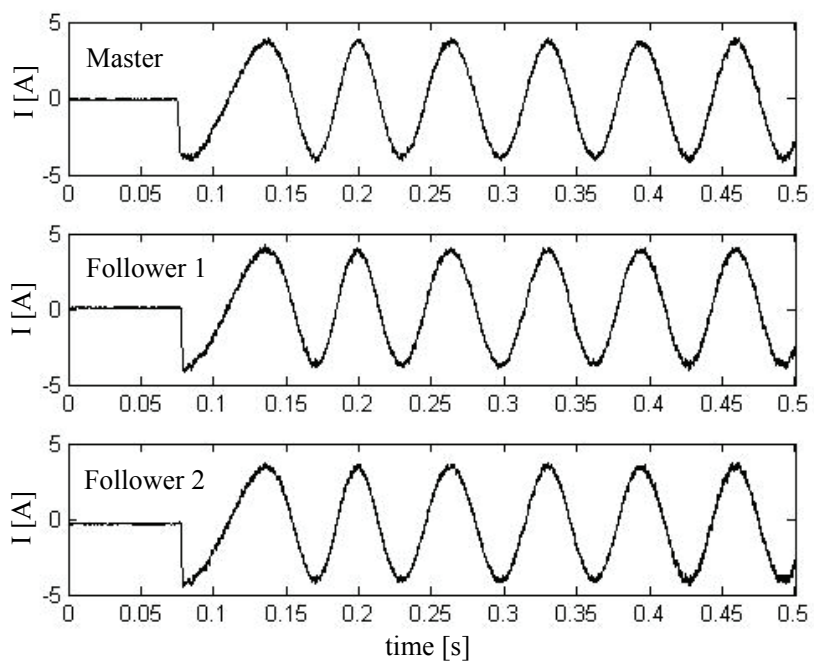

Fig. 13. Measured U-phase currents of the master and followers during starting the generator with $100 \%$ torque and $15 \%$ speed. Closed loop control with an absolute encoder.
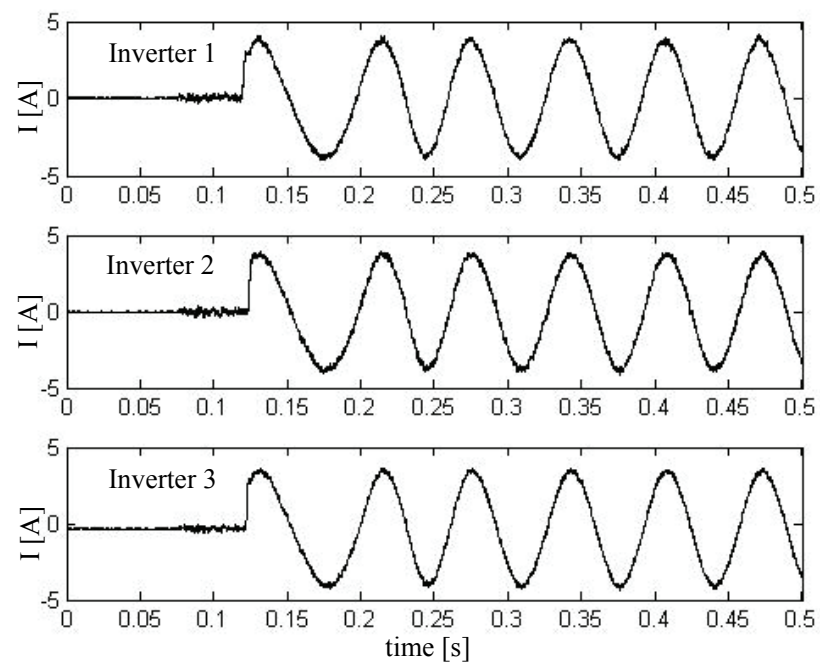

Fig. 14. Measured U-phase currents of inverter 1, 2, and 3, during starting the generator with $100 \%$ torque and $15 \%$ speed. Speed sensorless control.

to the closed loop control using the absolute encoder, is the start delay due to the flying start phase. This flying start phase is used to initialize the MRAS estimator and can be recognized in Fig. 14 as a $50 \mathrm{~ms}$ duration zero current phase at the beginning of the start.

Generator must be able to start also at higher speed than the $15 \%$ shown. If generator voltages are not measured, starting at higher speed using the sensorless control is more 
difficult than at lower speeds due to the higher back e.m.f. voltage of the generator. The higher the generator back e.m.f. voltage is, the faster the generator currents increase until the steady state condition is reached. However, starting at full speed is usually not a problem due to the fast current control response time. Fig. 15 shows the load machine torque calculated by the load machine inverter corresponding to the total torque produced
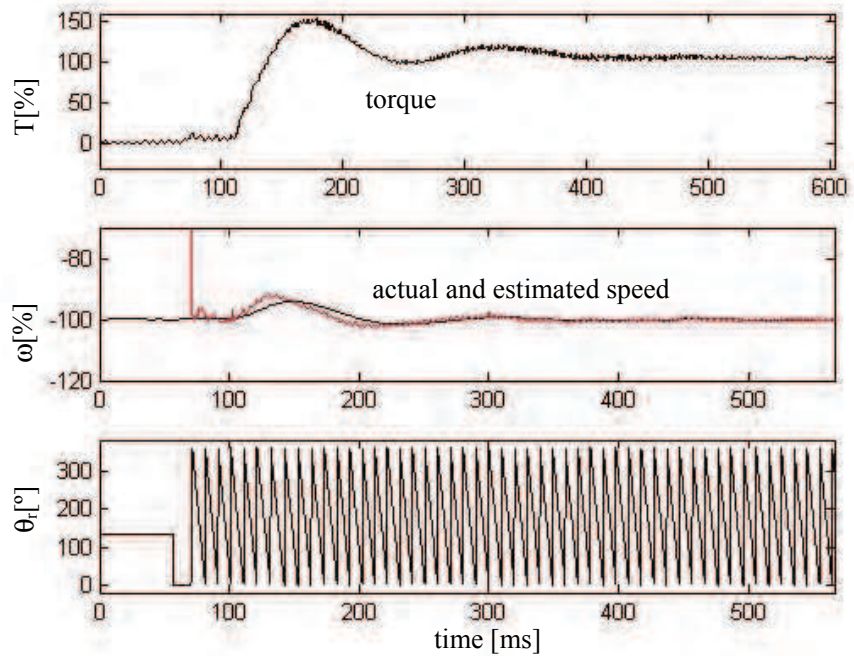

Fig. 15. Generator torque, estimated and measured speed, and the estimated rotor flux position $\theta_{\mathrm{r}}$. Generator is started at $100 \%$ speed and torque using the sensorless control.
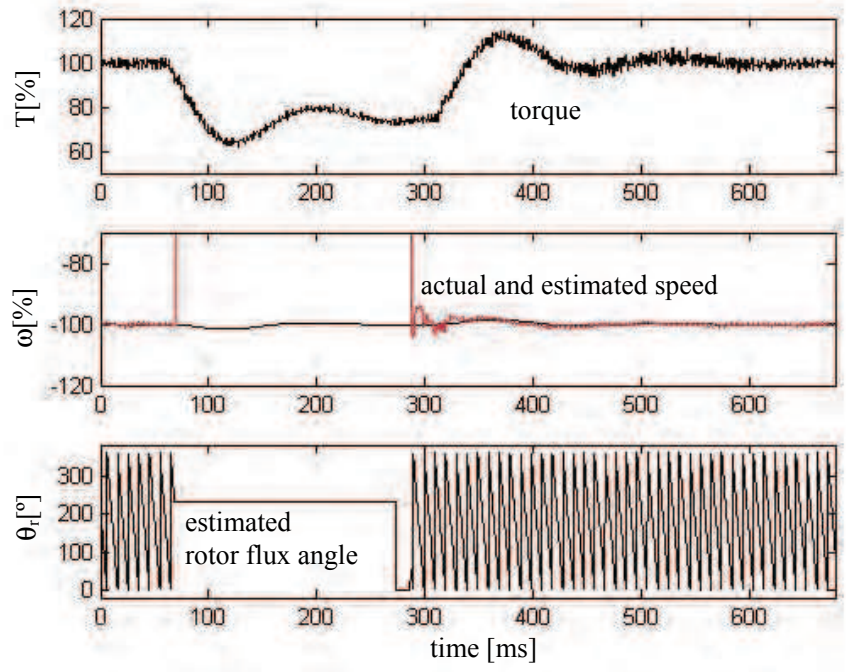

Fig. 16. Generator redundancy test: one of the four inverters is switched on fly off and on at $100 \%$ speed and torque command. 
by the generator when the generator is started at $100 \%$ speed. In addition, the estimated rotor flux angle, the estimated generator speed and the measured actual speed are also shown in Fig. 15.

The redundancy check was made by switching one of the four inverters on and off with the full torque command while the other one inverters continue the operation. This could happen, for example, if one of the inverters for some reason fails and is switched back on the fly. Such a situation is shown in Fig. 16, which shows the generator torque, the estimated and measured speed, and the rotor flux position when a one inverter is switched on and off at nominal speed. It can be seen that the generator can continue on running without the interruption if one (or more) of the inverters are switched off. Naturally, the generator power is reduced if all of the inverters are not in use.

\subsection{8 MW three segment generator}

Some test results are shown also for a real size 3.8 MW direct drive wind power generator manufactured by The Switch. The generator comprises three stator segments (Pyrhönen \& al, 2006) which are controlled using the sensorless control mode similar to the laboratory test generator described. The generator (Fig. 17) has about $6.6 \mathrm{~m}$ diameter and it weighs about $81000 \mathrm{~kg}$. Generator nominal values are given as: $U_{\mathrm{n}}=690 \mathrm{~V}, \mathrm{n}=17.5 \mathrm{rpm}, f_{\mathrm{n}}=17.5 \mathrm{~Hz}$, and $I_{\mathrm{n}}=3500 \mathrm{~A}$. At the moment, there are several of these or similar kind of generators in operation.
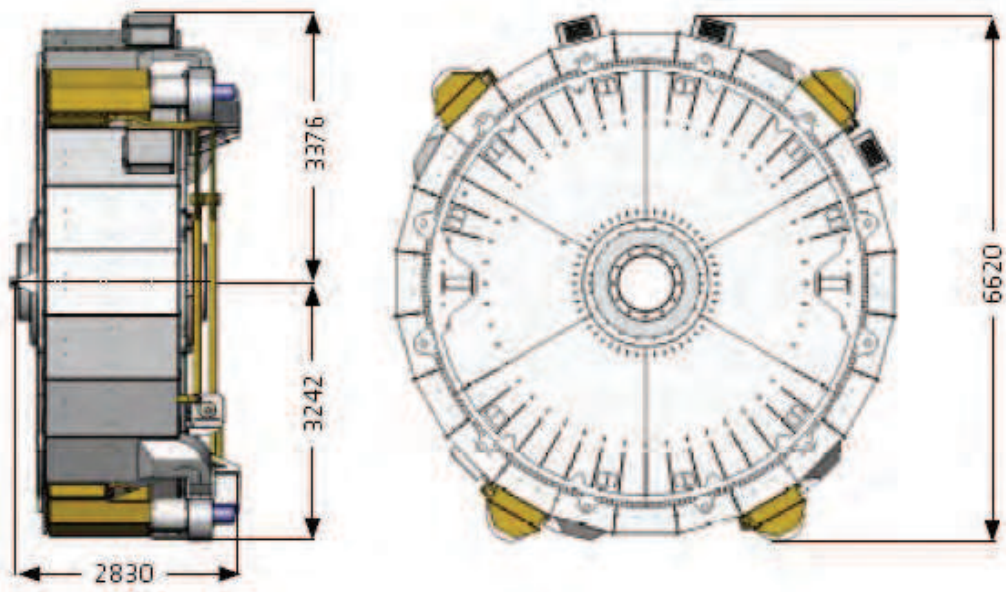

Fig. 17. 3.8 MW generator manufactured by The Switch: $n_{\mathrm{n}}=17.5 \mathrm{rpm}, f_{\mathrm{n}}=17.5 \mathrm{~Hz}$, $I_{\mathrm{n}}=3500 \mathrm{~A}, U_{\mathrm{n}}=690 \mathrm{~V}$ (Photo Courtesy of The Switch, Finland)

It is obviously expensive to build up test bench systems for this kind of large generators, which makes the small scale laboratory tests even more valuable. Normal laboratory tests are difficult due to the weight and size of the generator. Hence, most of the tests must be made during the factory installation or when the generator is in real operation. Some load tests can be made without the back-to-back connected generator-motor test benches due to the segment structure of the generator: one stator segment can be used to rotate the generator while the other segments are working in a generative mode. With this kind of test 
method, Fig. 18 shows a startup of one segment at the $20 \%$ generative torque. In this case, all the signals shown in Fig. 18 are measured or calculated by the segment inverter.
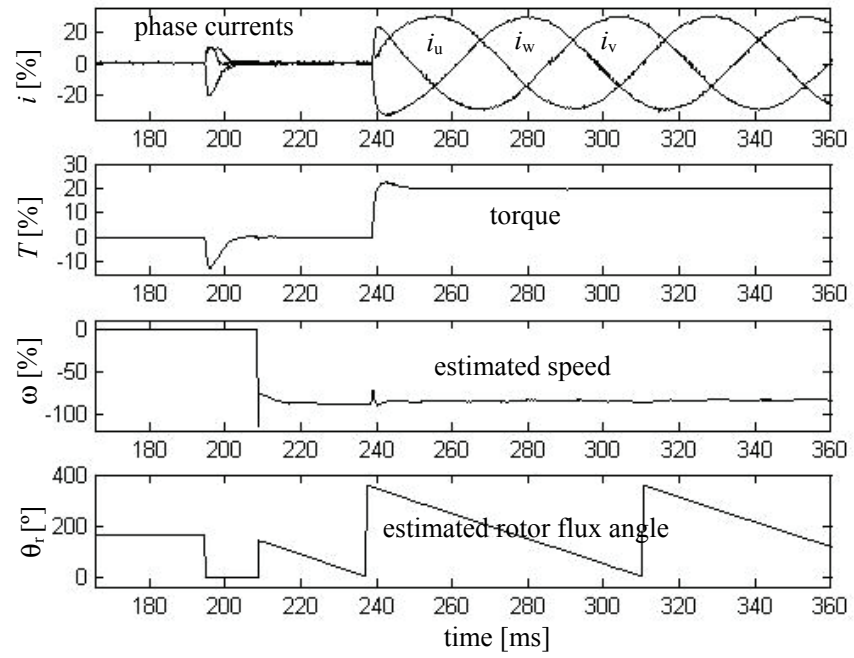

Fig. 18. Startup of one segment of the 3.8 MW generator at $20 \%$ torque. Inverter measurements for a segment torque, phase currents, and the estimated speed and rotor flux angle.

\section{Conclusions}

The reliability of high power drives can be increased using a generator/motor structure comprising multiple independent stator modules or segments each having an own drive inverter. In case that one of the inverters fails, the operation can continue by other inverters assuming that there is no failure in generator windings. In order to increase the drive system power level, several smaller inverter units can be used instead of a one larger one.

Wind power generators can operate long periods at reduced power due to the lack of sufficient wind. Hence, it is important that the generator operates at high efficiency also when operating below the nominal load point. The optimal efficiency is obtained only when the generator control is functioning in an optimal way, which is ensured by using the optimal vector control and the MTPA optimization which keeps the minimum stator current and the optimal stator flux level.

Wind power generators are a fast increasing application area requiring high power levels. It is a suitable application for the speed sensorless vector control described. Also, a principle of the closed loop control using an absolute encoder feedback was shown for the comparison. The test results with a small laboratory test bench confirmed the validity of the control methods and the idea of the redundancy. At the moment, several large scale $3.8 \mathrm{MW}$ permanent magnet generators comprising three stator segments are in operation in windmills. However, the applications of redundant drives are just not limited to the wind power production but the idea can be used everywhere requiring redundancy. For example, the same drive principle is used also in large $800 \mathrm{~kW}$ ski-lift motors comprising 8 stator segments and inverters. 


\section{References}

Albrich, R. \& Fuchs, E. (2002). Electric motor, United States Patent, Patent No.: 6,429,554, Aug. 2002.

Andreescu, G. D. (1999). Position and Speed Sensorless Control of PMSM Drives Based on Adaptive Observer, in Proc. 8th European Conference on Power Electronics and Applications (EPE'99), 10 p., 1999.

Halkosaari, T.H. (2007). Speed Sensorless Vector Control of a Redundant Permanent Magnet Wind Power Generator, in Proc. IEEE International Symposium on Industrial Electronics (ISIE 2007), pp. 2595-2600, 2007.

$\mathrm{Hu}$, J. \& Wu, B. (1998). New integration algorithms for estimating motor flux over a wide speed range, IEEE Transaction on Power Electronics, Vol. 13, No. 5, September 1998, pp. 969-977.

Mäkinen, J-P.; Haapamäki, P. \& Halkosaari T. (2006). Control of parallel operation of frequency converters or inverters, United States Patent, Patent No.: 7,038,405, May 2006.

Pyrhönen, J.; Kurronen, P. \& Parviainen, A. (2006). Permanent Magnet 3 MW Low-Speed Generator Development, in Proc. XVII International Conference on Electrical Machine (ICEM2006), 2006. 


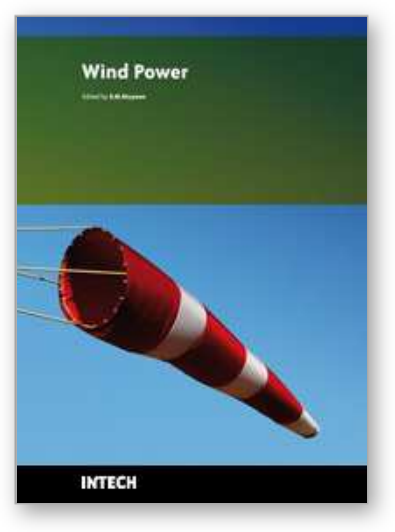

\author{
Wind Power \\ Edited by S M Muyeen
}

ISBN 978-953-7619-81-7

Hard cover, 558 pages

Publisher InTech

Published online 01, June, 2010

Published in print edition June, 2010

This book is the result of inspirations and contributions from many researchers of different fields. A wide verity of research results are merged together to make this book useful for students and researchers who will take contribution for further development of the existing technology. I hope you will enjoy the book, so that my effort to bringing it together for you will be successful. In my capacity, as the Editor of this book, I would like to thanks and appreciate the chapter authors, who ensured the quality of the material as well as submitting their best works. Most of the results presented in to the book have already been published on international journals and appreciated in many international conferences.

\title{
How to reference
}

In order to correctly reference this scholarly work, feel free to copy and paste the following:

Tero Halkosaari (2010). Speed Sensorless Vector Control of Permanent Magnet Wind Power Generator - The Redundant Drive Concept, Wind Power, S M Muyeen (Ed.), ISBN: 978-953-7619-81-7, InTech, Available from: http://www.intechopen.com/books/wind-power/speed-sensorless-vector-control-of-permanent-magnet-windpower-generator-the-redundant-drive-concept

\section{INTECH}

open science | open minds

\section{InTech Europe}

University Campus STeP Ri Slavka Krautzeka 83/A 51000 Rijeka, Croatia

Phone: +385 (51) 770447

Fax: +385 (51) 686166 www.intechopen.com

\section{InTech China}

Unit 405, Office Block, Hotel Equatorial Shanghai No.65, Yan An Road (West), Shanghai, 200040, China 中国上海市延安西路65号上海国际贵都大饭店办公楼405单元 Phone: +86-21-62489820

Fax: +86-21-62489821 
(C) 2010 The Author(s). Licensee IntechOpen. This chapter is distributed under the terms of the Creative Commons Attribution-NonCommercialShareAlike-3.0 License, which permits use, distribution and reproduction for non-commercial purposes, provided the original is properly cited and derivative works building on this content are distributed under the same license. 